\title{
Geometric and strain analyses in folds of the area around Gankot, district Pithoragarh, Uttarakhand, India
}

\author{
Swati Lata ${ }^{1}$, Ravindra Kumar ${ }^{2}$, Vaibhava Srivastava ${ }^{1}$ \\ ${ }^{1}$ Banaras Hindu University, Center of Advanced Study, Department of Geology, Varanasi, -221005, India \\ ${ }^{2}$ Babasaheb Bhimrao Ambedkar University, Department of Earth Sciences, Lucknow, -226025, India
}

* Corresponding author : swatilata4@gmail.com

Received: Oct 17, 2018; Accepted: Feb 22, 2019.

DOI: 10.25299/jgeet.2019.4.2-2.2237

\begin{abstract}
The study area around Gankot in Pithoragarh district of Uttarakhand belongs to the Thalkedar Limestone unit of Mandhali Formation, Tejam Group in Inner Sedimentary Zone of Lesser Himalaya, which exposes complexly folded and refolded structures. Geometric analysis carried out on the profile section of the fold tracing using dip isogon and orthogonal thickness parameters revealed presence of all the fold geometry suggested by Ramsay (1967) however the class 3 followed by class 1B are the most dominant classes in the study area when individual layers of the fold were studied. The study of folds as multilayered unit reveals that folds in study area belong to strongly non-analogous fold class of anisodeviatoric folds. In fold, the strain analysis has been done by drawing strain ellipse obtained by Inverse Thickness Method which is useful in estimating flattening strain even when the flattening is imposed obliquely to the fold's axial trace. The finite two-dimensional flattening strain ratio (Rs) value ranged between 1 and 3.14 with an average Rs value of 1.60 . The method of Srivastava and Gairola (2003) has also been used to obtain shear strain and flattening strain for the multilayered folds of study area. The results reveal that the multilayered folds around Gankot area are moderately flattened with mean flattening strain varying between 1.06 and 2.28. A very high degree of variation in shearing ranging about 700 in both clockwise and anticlockwise directions has been noticed. The shear strains $(\gamma)$ in folds have been found to vary between -2.75 to +3.27 with an average of +0.33 . The shearing and strain patterns are suggestive that the most dominant folding mechanism has been the flexure-shear for the folds of the study area which are overprinted by the fold flattening and other subsequent deformations.
\end{abstract}

Keywords: Fold geometry, Strain, Flattening, Shearing, Lesser Himalaya, Multilayered fold

\section{Introduction}

The folded layer may or may not maintain uniform thickness across the full profile view of the fold. The variation of fold geometry within a rock layer during folding depends on the internal stresses it is forced to bear and the rock's strength to resist. The variation in fold geometry can be analyzed by the use of dip isogons- which are the lines obtained by connecting points of equal inclination on the outer and inner bounding surfaces of the folded layers (Elliott 1965). Ramsay (1967) introduced the concepts of thickness parameters such as t' $\alpha$-the orthogonal thickness parameter and $T^{\prime} \alpha$-the axial plane parallel thickness parameter in the folded layers and developed a scheme of fold classification based on variations in these thickness parameters with respect to dip angle $\alpha$. Based on the pattern of variation Ramsay (1967) and Ramsay and Huber (1987) classified fold layer geometry as class 1A, 1B, 1C, 2 and 3. Later Zagorčev (1993) extended the fold class to include further more categories as $1 \mathrm{~A} 1,1 \mathrm{~A} 2,1 \mathrm{~A} 3,3 \mathrm{~A}, 3 \mathrm{~B}$ and $3 \mathrm{C}$ classes in $1 \mathrm{~A}$ and 3 classes respectively. These classification schemes hold good to describe the geometry in a single layer of the fold. In nature however, most of the folds occur as multilayered sequence. In field the folds may or may not exhibit simplicity due to variations in the amount and direction of applied stresses, composition, viscosity, porosity, shape and size of grains in different layers, thus the variety of intermediate fold types are found. To describe the degree of variation in the geometry of constituents layers in multilayered fold a few schemes of classification exclusively for multilayered folds, were developed by Srivastava and Gairola (1997, 1999, and 2003). The study of geometry of the folds is often useful in interpreting the mechanism of fold development in a region. Therefore, in present work the geometry of folds in Mandhali Formation around Gankot village (Fig.1) of Pithoragarh district of Lesser Kumaon Himalaya have been studied to know about the possible fold development mechanism which might be significant in deducing the overall tectonic history of the area. In this work the analysis of the fold have also been done to obtain the flattening strain too by using method of Srivastava and Gairola (2003). 


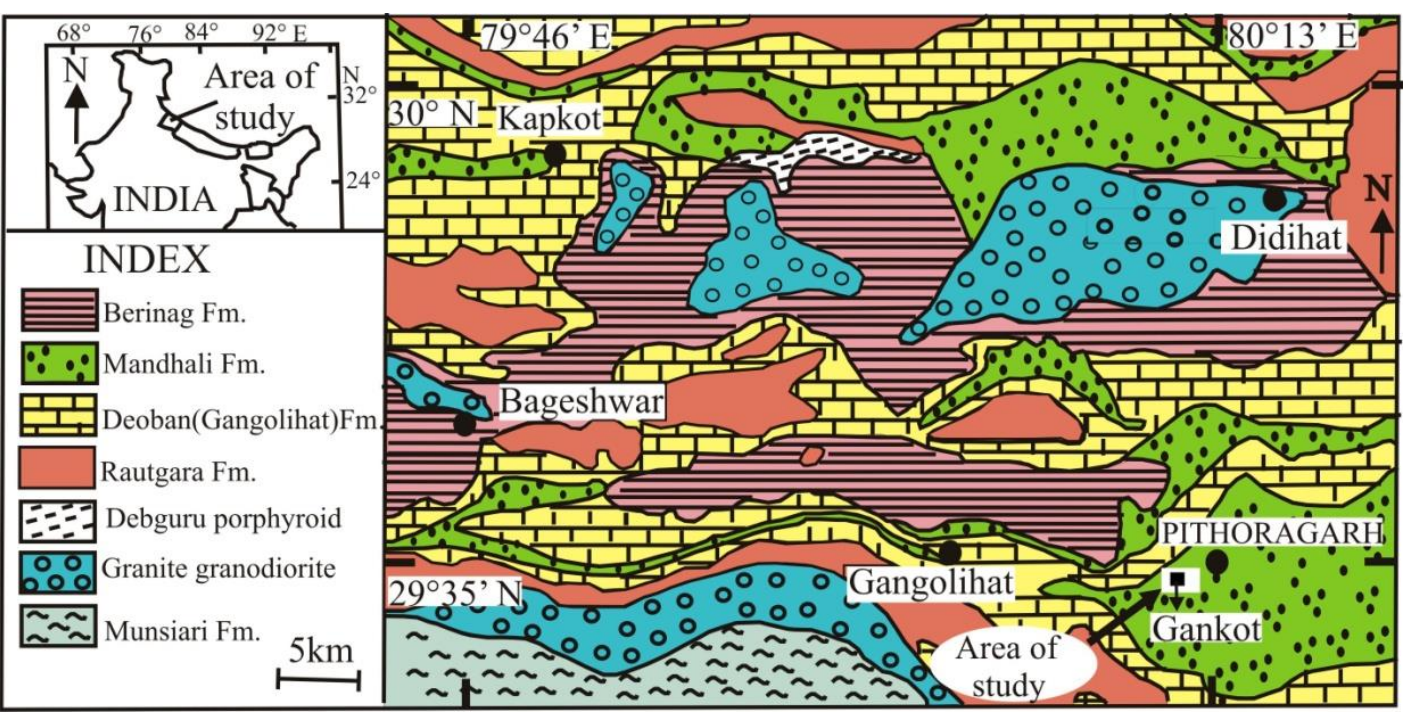

Fig. 1. Location of study area around Gankot in the geological map of a part of Kumaon Himalaya (after Valdiya 1980).

\section{Geology of the area}

There has been significant contributions on the geology of Kumaon Himalaya by workers like Rupke (1974), Valdiya (1980) , Chamyal (1991), Azmi and Paul (2004), Tiwari (2008), Rao and Sharma (2009, 2011), Patel et al. (2011) and Chakrabarti (2016). The study area around Gankot lies in the Kumaon Himalaya in Pithoragarh district of Uttarakhand between latitudes $29^{\circ} 34^{\prime} \mathrm{N}$ to $29^{\circ} 34^{\prime} 45^{\prime \prime} \mathrm{N}$ and longitudes $80^{\circ} 10^{\prime} 45^{\prime \prime} \mathrm{E}$ to $80^{\circ} 12^{\prime} 45^{\prime \prime} \mathrm{E}$. The rocks of the study area bel ong to the Inner Sedimentary Belt of Lesser Himalaya and form a part of the Mandhali Formation (Sor + Thalkedar Formation) of Lesser Kumaon Himalayan region (Valdiya, 1980: Fig. 1). The study area is located around north and north-western margin of Majhaon Danda hill (Elev. 1826m) dominantly consisted of carbonate rocks. The lithology belongs to Calc zone of Pithoragarh, as it is consisted dominantly of dolomitic limestone, limestone, slaty limestone and slate indicative of low grade regional metamorphism in the region. According to Valdiya (1980) the syncline is present between the Bhalpatal Dhar (Elev. 1941m) to Majhaon Danda (Elev. 1826m) which is well discernible between Balkot through Bisar to Paganna and Hureti. The rock types found in the study area during field survey are phyllitic limestone (argillaceous limestone), laminated limestone, grey coloured massive dolomitic limestone, slate and dolerite. The structural analysis has been carried out considering the geological structures as planar fabrics, linear fabrics and fold. The area has experienced at least three stages of ductile deformation under compressional tectonics causing development of three generation of folds and thus exhibiting a complex folded sequence of rocks. The aim of the present work however, is focused on analyzing the geometry of the mesoscopic folds found in the study area and flattening strain and shearing experienced by these folds.
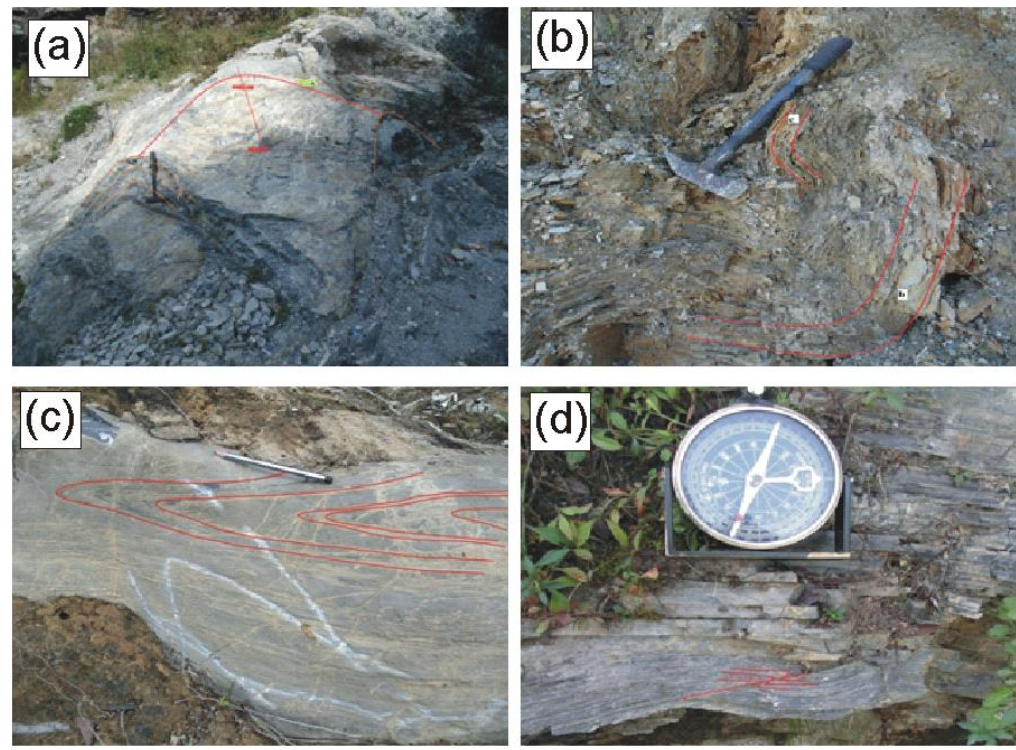

Fig. 2. Mesoscopic structures showing refolding in limestone ( $a$ and c) and slate (b) and shearing in limestone (d) of the study area 


\section{Analysis of fold profile geometry}

The study area around Gankot village in Pithoragarh district of Uttarakhand possesses complex but interesting structures:Fig. 1. The field observations are indicative that the entire area has undergone repeated phases of deformation as a result of multi-phased Himalayan orogeny resulting into an intricate system of superimposed folds, faults and fracture development at different scales:Fig. 2. In the study area although folds are present in all rocks at all scales from microscopic, mesoscopic to macroscopic levels, the mesoscopic folds have been chosen for geometrical analysis for convenience in the study.

In order to geometrically analyze the fold in present study the folds have been traced from field photographs, field tracings and cut-and polished sections of the hand specimen samples. Cares have been taken so that the tracings as far as possible represent the profile section of the fold. These fold profiles al ong with their dip isogons have been presented in Fig. 3.
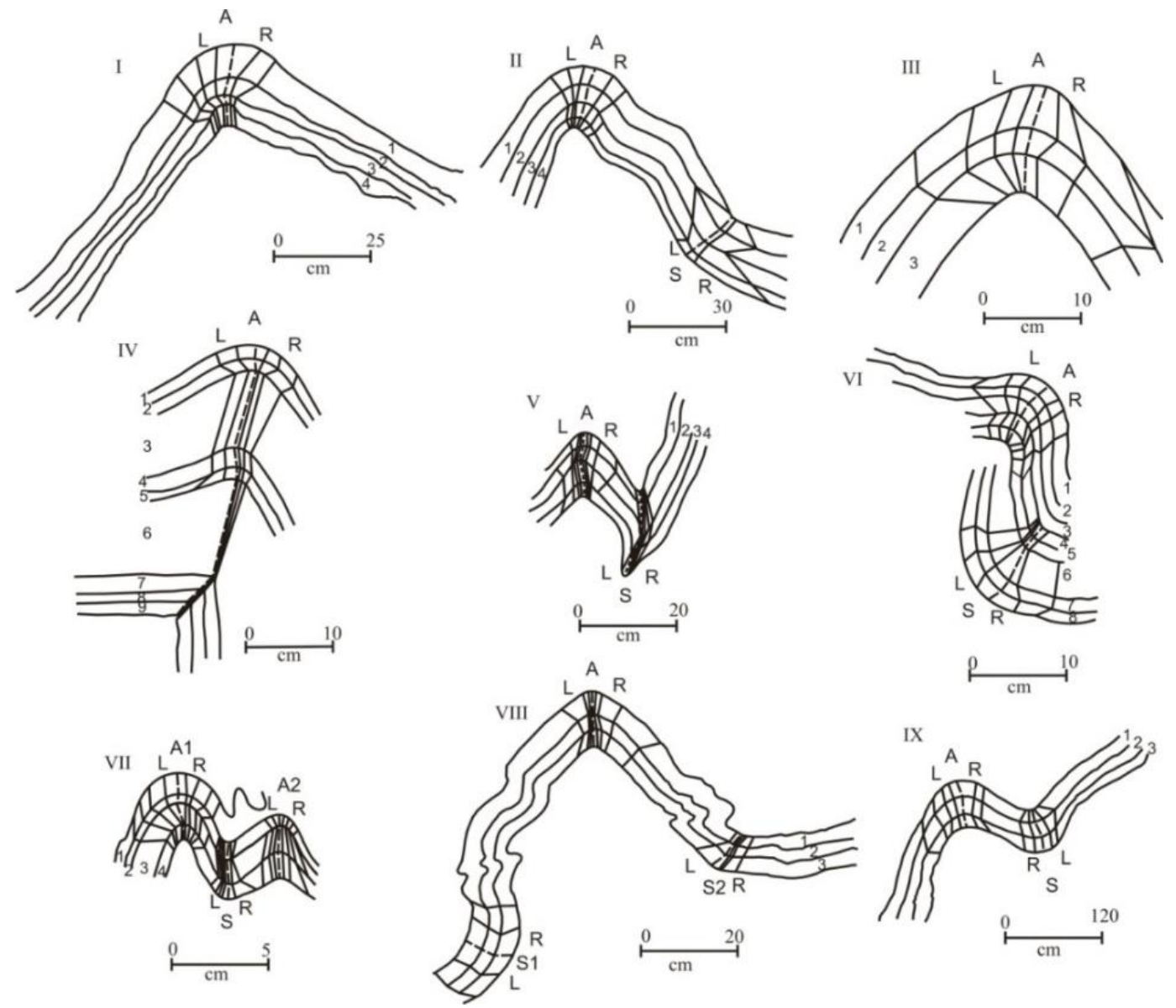

Fig. 3. Dip isogons on the tracings of profile sections of folds from the study area.

In order to analyze the geometry according to Ramsay (1967) the orthogonal thickness $t_{\alpha}$ were measured from the limbs of each fold layer separately on the fold profile. The orthogonal thickness parameter $t^{\prime} \alpha$ were obtained by dividing $t_{\alpha}$ with $t_{0}\left(t_{\alpha}^{\prime}=t_{\alpha} / t_{0}\right)$, where $\alpha$ is the dip angle which is taken at interval of $10^{\circ}$ in present work. Fig. 4 represent the plots of a representative fold profile on the standard set of $t_{\alpha}^{\prime}$ versus $\alpha$ diagram given by Ramsay (1967) for the geometric analysis of the folds. The plots are indicative that folds of the study area do not restrict themselves to a particular type of fold geometry rather, a large variation is observed in them. The folds in fact, show that all type of geometries suggested by Ramsay and Huber (1987) but in differing proportions. Therefore, in order to obtain a meaningful interpretation the results have been subjected to further statistical analysis and presented with help of a bar diagram in Fig. 5. It can now be concluded with the help of Fig. 5 that the folds of the study area mostly exhibit class 3 fold geometry which accounts near $50 \%$ of all fold types, followed by $1 \mathrm{~B}(27 \%)$ and $1 \mathrm{~A}(15 \%$. The Class $1 \mathrm{C}(7 \%)$ and class $2(1 \%)$ fold geometries are less abundant. It was also observed that the most abundant classes (i.e. class3 and class 1B) receive good contributions from isogons from increasing $\alpha$ value. The high abundance of class 3 geometry suggests that major fold mechanism has been the differential compression in the area. However, other mechanism such as flexural folding (1B) and fold flattening $(\mathrm{IC})$ are also important. The passive shear folding mechanism which is generally responsible for class 2 geometry is rare. 


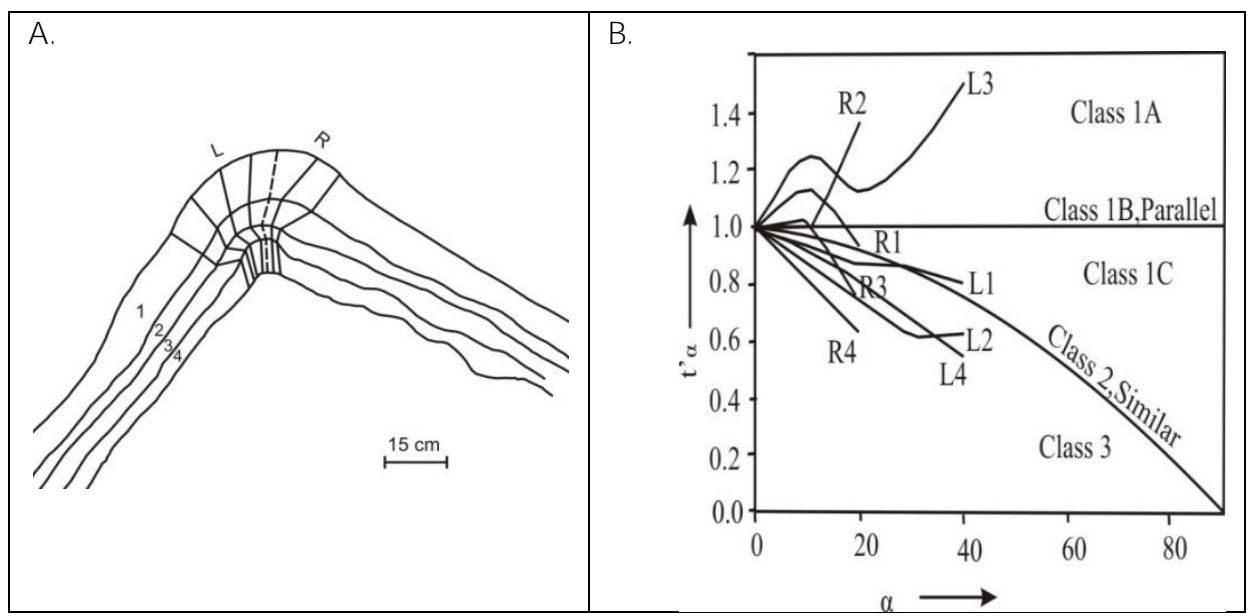

Fig. 4. (A) Dip isogons on a representative fold profile from study area . (B) Ramsay's (1967) plot of orthogonal thickness parameters $\mathrm{t}_{\alpha}$ versus dip angle $\alpha$ for the fold profile geometry shown in $A$. $L$ and $R$ represent left and right limbs of the fold respectively, and 1, 2, 3 and 4 for their constitutive layers.

\section{Geometrical analysis of multilayered fold}

The folds of the study area generally multilayered therefore they have been studied as multilayered sequence too using the scheme given by Srivastava and Gairola (1999). The scheme utilizes the variation in the fold geometry of each constituting layers of a multilayered fold at a particular dip isogon $(\alpha)$ by obtaining the standard deviations of $\left(\mathrm{t}_{\alpha}^{\prime}\right)$ values. Fig. 6 represents the plot given by Srivastava and Gairola (1999), in which all the curve a, b, c, and d are originated from the origin point and separating the two different geometric class.

If the plot of the fold is lying parallel to the abscissa it is called 'Isodeviatoric fold' and if not, they are termed as 'Anisodeviatoric fold'. A special variety of Isodeviatoric fold in which all the layers exhibit the same kind of geometry has been termed as 'analogous fold'. The anisodeviatoric folds have been further subdivided into perianalogous, sub-analogous, sub-nonanalogous, nonanalogous, and strongly nonanalogous fold classes. The data obtained from the analyzed multilayered folds of the study area are plotted and given in Fig. 6 .

The multilayered folds of the study area (Fig.3) were treated according to Srivastava and Gairola (1999) and thereafter plotted in the their standard graph(Fig. 6). It has been found that the majority of the folds of the study area belong to the strongly non-analogous fold category. Fig. 6 reveals that the folds do not exhibit definite fold geometry and the plots are distributed in more than one class. Therefore, the fold data were once again analyzed to know their frequency in different classes and the analysis is presented with the help of bar diagram in Fig. 7. It reveals that though fold data fall in almost all the classes but majority of the folds belong to the strongly nonanalogous class. This indicates that the folds of the Gankot area do not have regular geometry in the multilayered sequence and the degree of variation is very high suggesting strong influence of multiple phased deformations on these folds. The great deviation from any consistent regular fold geometry may be the effects of folding and refolding which are often visible in the rocks of the study area: Fig. 2.

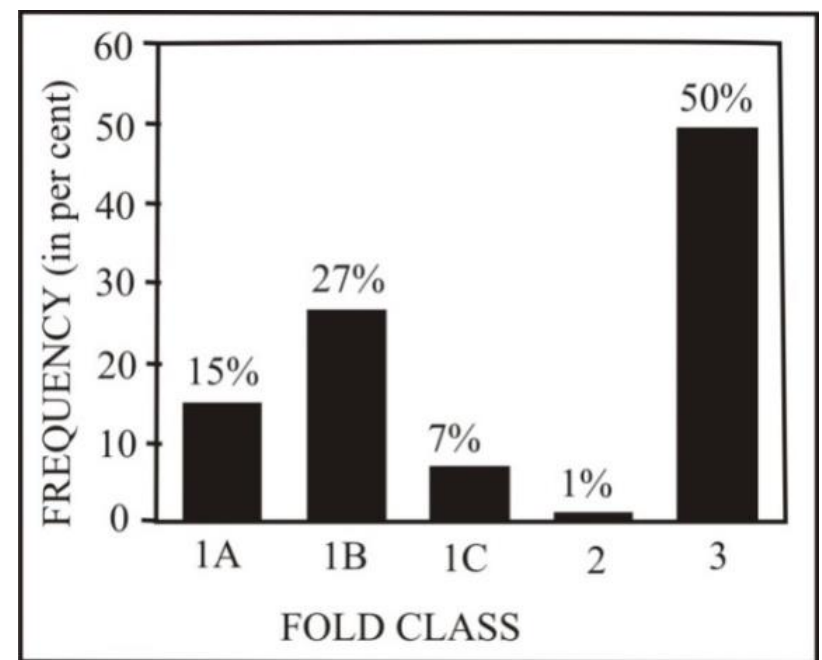

Fig. 5. Bar Diagram showing frequency of different fold classes (Ramsay, 1967) in the study area. 


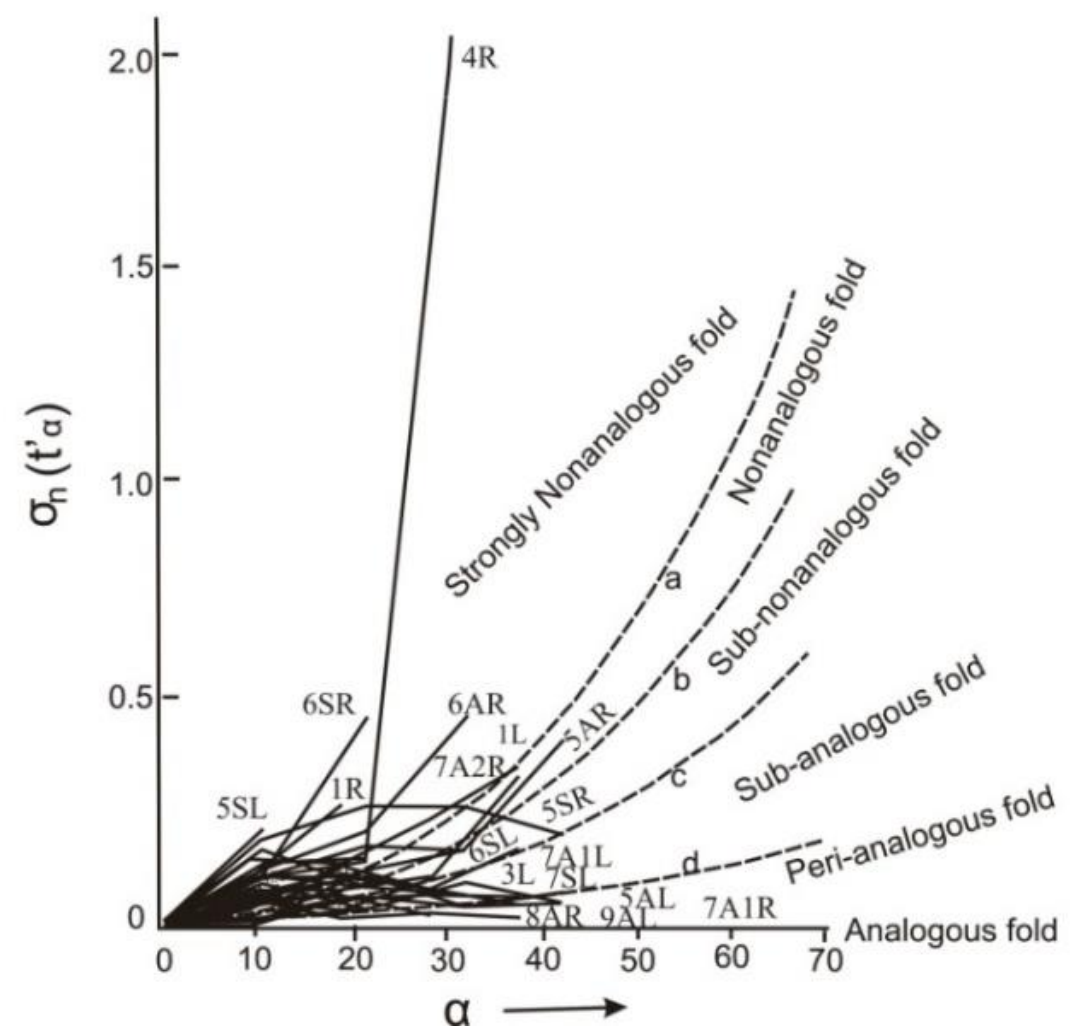

Fig. 6. Variation in geometry of multilayered folds of the study area plotted in standard $\sigma_{\mathrm{n}}\left(\mathrm{t}_{\alpha}{ }_{\alpha}\right)$ versus Dip angle $\alpha$ diagram (after Srivastava and Gairola, 1999); A, S, R, and L represents fold, antiform, synform, right limb and left limb respectively for folds (Fig.3).

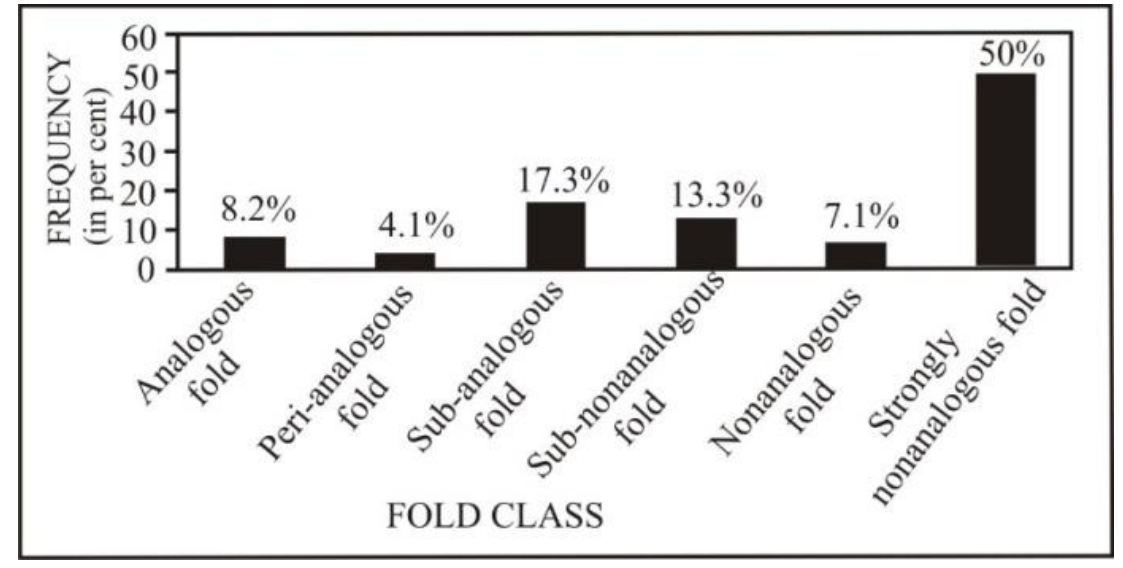

Fig. 7. Frequency distribution of mesoscopic multilayered folds classes (Fig.3\& Fig. 6) of study area.

\section{Flattening and Shearing in Folds}

A buckle or flexure fold does not change the orthogonal thickness of the layer, therefore such folds exhibit class 1B geometry. However, if the folds are subsequently compressed the layers fail to maintain this thickness and they change their geometry from class 1B to $1 \mathrm{C}$ because of flattening. Thus a unit circle of 1B fold obtained by inverse thickness method (Lisle 1992) changes to an ellipse; the axial ratio of this ellipse gives the finite flattening strain ratio (Srivastava and Gairola 2003). The folds after their formation due to progressive deformation or subsequent co-axial deformation may undergo flattening. Sometimes the flattening may be associated with shearing also that may also be recognized by the method of Srivastava and Gairola (2003). Thus the method is often useful not only in partitioning out the flattening strain but it is also capable of detecting the sense of rotation by shearing. In fold, the strain analysis has been done by drawing strain ellipse obtained by "Inverse Thickness Method" proposed by Lisle (1992) and Srivastava and Gairola (2003) which is useful in estimating flattening strain even when the flattening is imposed obliquely to the fold's axial trace. The method has been applied on the folds of the study area and a part of which is given in Fig. 8. 


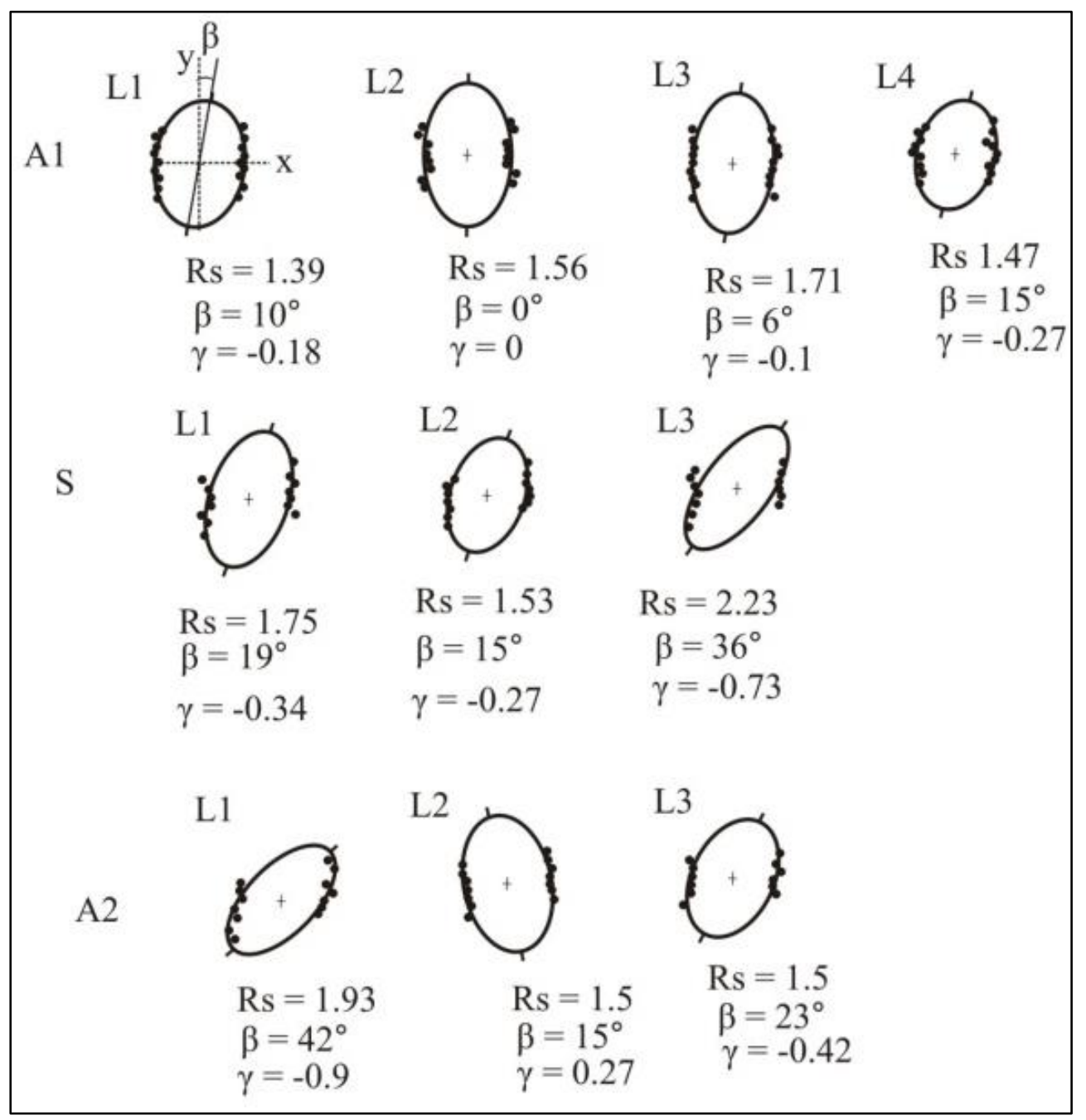

Fig. 8. Flattening strain estimation for fold layers (of fold no VII, Fig.3); $R_{5}=$ Finite 2-D flattening strain ratio; $\beta=$ Inverse Shear angle $(\beta=-\psi)$; Shear strain $\gamma=\tan \psi$ (after Srivastava and Gairola, 2003).

A total of 67 limbs of the folded layers belonging to 10 different multilayered folds comprising of 3 to 5 layers have been analyzed and the results are presented in Table 1 . The folds are widely distributed over the study area and it was observed that the finite two-dimensional flattening strain ratio $\left(R_{s}\right)$ values range between 1 and 3.14 with an average $R_{s}$ value of 1.60 . It suggested that at places the fold layers of the study area have remained unflattened $\left(R_{s}=1\right)$ while at other places they are subjected to high degree of flattening. As a multilayered unit the folds of the study area have shown Mean Finite Flattening Strain Ratio (Mean $R_{s}$ ) values from 1.06 to 2.28. Following Srivastava and Gairola (2003) a total of 64 limbs of the folded layers belonging to 10 different multilayered folds comprising of 3 to 4 layers have been analyzed for shear strain $(\gamma)$ and the results are presented in Table 2. Representative analysis of a multilayered fold is given in Fig. 8 as well. Table 2 reveals that shear strain is not uniformly distributed in the folded layers and it varies between -2.75 and +3.27 . The negative sign is indicative of anticlockwise and the positive sign is for clockwise sense of shearing. These extreme values of shear strain $(\gamma)$ correspond to the shear angle $(\psi)$ as high as $-70^{\circ}$ to $+73^{\circ}$ in the individual layers however the mean shear angle $(\psi)$ remains $\sim 18^{\circ}$ in clockwise direction. It was also observed that the different constituting layers of a single multilayered fold have shown positive and negative shear senses which indicate that shear strain have been developed and received differently by the individual layers due differing slippage among the constituting layers. The variation in amount of shear strain and sense may be attributed to differing compositions and other mechanical anisotropies of the constitutive layers of the fold. When analyzed as multilayered fold, the average shear strain (Mean $\gamma$, Table 2) were found to vary between -0.56 to +2.70 within an individual fold but the overall average of the 10 multilayered fold $(+0.33)$ account for the low overall shearing of the folds which accounts for only $18^{\circ}$ of general overall shear angle $(\psi)$. However there might be great fluctuation form this mean shear strain (Mean $\gamma$ ) of a multilayered fold and standard deviation may be as high as 1.91. Therefore it seems that the shearing in the folded layers is mainly due to the slippage among different 
constituting layers of the folds which is indicative that perhaps the dominant folding mechanism seems to be the flexure-shear mechanism (Twiss and Moores, 2007).

Table 1

Finite 2-D Flattening Strain Ratio $\left(R_{s}\right)$ obtained from different multilayered folds from the study area.

\begin{tabular}{ccccccc}
\hline FOLD NO. & L1 & L2 & Llattening Strain Ratio $\left(R_{s}\right)$ & L4 & L5 & MEAN $R_{s}$ \\
\hline II & 1.59 & 2.77 & 2 & 2.77 & - & 2.28 \\
IIA & 1.47 & 1.11 & 1.11 & 1.92 & - & 1.4 \\
IIS & 1.85 & 1.33 & 1.26 & 2 & - & 1.61 \\
III & 1.6 & 1.81 & 1.75 & - & - & 1.72 \\
IV & 1.46 & 1 & 1.57 & 1.68 & 1.04 & 1.35 \\
VA & 1.79 & 1.47 & 1.68 & 1.75 & - & 1.67 \\
VS & 3.14 & 1.65 & 2.07 & 1.42 & - & 2.07 \\
VIA & 1.31 & 2 & 1.87 & 1.47 & 1.47 & 1.62 \\
VIS & 1.85 & 2.82 & 1.56 & 1.35 & 1.69 & 1.85 \\
VIIA1 & 1.39 & 1.56 & 1.71 & 1.47 & - & 1.53 \\
VIIA2 & 1.93 & 1.5 & 1.5 & - & - & 1.64 \\
VIIS & 1.75 & 1.53 & 2.23 & - & - & 1.84 \\
VIIIA & 1.71 & 1.19 & 1.39 & - & - & 1.43 \\
VIIIS1 & 1.05 & 1.04 & 1.72 & - & - & 1.27 \\
VIIIS2 & 1.67 & 1.8 & 1.48 & - & - & 1.65 \\
IXA & 1.4 & 1.53 & 1.67 & - & - & 1.53 \\
IXS & 1.05 & 1.05 & 1.07 & - & - & 1.06 \\
X & 1.17 & 1.17 & 1.18 & 1.18 & - & 1.18 \\
\hline \multicolumn{7}{c}{ Average } \\
\hline
\end{tabular}

Table 2

Shear Strain $(\gamma)$ obtained from different layers of folds from the study area.

\begin{tabular}{ccccccc}
\hline FOLD NO. & L1 & SHEAR STRAIN $(\gamma)$ & L2 & L3 & Mean $\gamma$ & SD \\
& 1.43 & 1.73 & -2.75 & 1 & 0.35 & 1.81 \\
I & 1.8 & 0.12 & 0.12 & 2.75 & 1.20 & 1.13 \\
II,A & 2.9 & 3.27 & 1.88 & 2.75 & 2.70 & 0.51 \\
II,S & 0.14 & -0.14 & -0.18 & - & -0.06 & 0.14 \\
III & -2.75 & 0 & 0.09 & -0.58 & -0.81 & 1.15 \\
IV & 0.81 & 0.55 & 0.23 & 0.58 & 0.54 & 0.21 \\
V,A & 1.11 & 1.73 & 1 & -0.58 & 0.81 & 0.85 \\
V,S & 1.67 & 1.19 & -0.84 & 0.36 & 1.59 & 1.09 \\
VI,A & 2.75 & -1.54 & -1.73 & -1.73 & -0.56 & 1.91 \\
VI,S & -0.18 & 0 & -0.1 & -0.27 & -0.14 & 0.1 \\
VII,A1 & -0.9 & 0.27 & -0.42 & - & -0.35 & 0.48 \\
VII,A2 & -0.34 & -0.27 & -0.73 & - & -0.45 & 0.2 \\
VII,S & -0.47 & -0.36 & -0.27 & - & -0.37 & 0.08 \\
VIII,A & -0.21 & 0 & 1.19 & - & 0.33 & 0.62 \\
VIII,S1 & -0.21 & 2.47 & 2.9 & - & 1.72 & 1.38 \\
VIII,S2 & -0.31 & -0.09 & 0.18 & - & -0.07 & 0.2 \\
IX,A & -0.84 & -0.18 & 0 & - & -0.34 & 0.36 \\
IX,S & 0.27 & 0.3 & -0.1 & -0.1 & 0.09 & 0.21 \\
X & 0 & Average & & & +0.33 &
\end{tabular}

\section{Discussion and Conclusion}

Many workers have discussed about the Kumaon Himalaya pertaining to different aspects of structure and tectonics in this region (Bhattacharya, 2008; Valdiya and Pande, 2009; Joshi and Tiwari, 2009; Agarwal et al. 2010, 2016; Agarwal and Sharma, 2011; Bhargava, 2011; Patel et al., 2007, 2011; Srivastava et al. 2011; Verma and Bhattacharya, 2011; Jain et al. 2012, 2016; Shah et al, 2012; Singh et al., 2012; Jade et al. 2014; Dubey 2014; Banerjee et al. 2015; Bhattacharya and Ahmed 2016)and their works have thrown much light on the tectonic evolution of the rocks of the region which are highly folded and tectonically much complex. The mesoscopic folds have been used by many workers for the analysis of the folding and the strain conditions (Dieterich and 
Carter, 1969; Roberts and Strömgard, 1972; Hudleston, 1973; Sanderson, 1976; Bhattacharya, 1978; Hudleston, and Holst, 1984; Lisle, 1992; Bastida, 1993; Bastida et al., 2003; Srivastava, 1995, 2003; Srivastava and Gairola, 2003). To unravel the complexities of the fold geometries significant work include those by Srivastava and Sinha (1987); Jain and Anand (1988); Srivastava et. al.(2011); Katiyar and Srivastava (2012) which have utilized the fold profiles of mesoscopic folds in Himalayan region. The present study area which belongs to the Thalkedar limestone unit of Mandhali Formation, Tejam Group of Lesser Himalaya, district Pithoragarh possesses complexly folded sequence of limestone and slate. On the basis of presence of microfossils, Tiwari and Pant (2009) consider the Gangolihat Limestone of Kumaon Himalaya as Neoproterozoic age. The folding in these Neoproterozoic rocks must have been developed in multiple phases during the Himalayan Orogeny in Tertiary. Patel et al. (2011) recognized four phases of deformation $\left(D_{1}\right.$ to $\left.D_{4}\right)$ in the Higher Himalayan Crystallines of Kumaun Himalaya, which are responsible for complex geometries of the folds in the region. Analysis of fold geometry and strain in this region however, is very much lacking. In the present study our aim is to quantify the overall deformation status in terms of strain and shearing in the mesoscopic folds without differentiating the folds of different generations. Therefore, in the present work we have attempted not only the geometric analysis of the mesoscopic folds but the flattening strain conditions after their formation is also discussed. We have applied the schemes proposed by Srivastava and Gairola (1999 and 2003) for the folds of study area because this scheme allows the fold to be studied as multilayered sequence too. The study reveals that folds in study area belong to strongly non-analogous fold class of anisodeviatoric fold of Srivastava and Gairola (2003). Most of the folds of the study area however exhibit class 3 fold geometry which is indicative that thickness of the layers in limb portion is much less than those at the hinge zone. This may be due to the additive deformation caused by subsequent folding, refolding, flattening and shearing etc. after the first folds were formed. However the class 3 geometry is next succeeded in abundance by class 1B geometry of Ramsay (1967) which reveals that a significant number of the folds in the study area have still maintained their orthogonal thickness perhaps because some of the layers were compositionally competent enough and were not significantly affected by later deformations. The subsequent deformations however, are arrested in folds in the comparatively less competent layers in the form of flattening strain and shearing which have been partitioned out by the method after Srivastava and Gairola (2003). The finite two-dimensional flattening strain ratio $\left(R_{s}\right)$ value ranged between 1 and 3.14 with an average $R_{s}$ value of 1.60 in individual folded layers however, in multilayered folds around Gankot area it varied between 1.06 and 2.28 which is suggestive of moderate flattening in the folds in general. The shear strains $(\gamma)$ in folds have been found to vary between -2.75 to +3.27 with an average of +0.33. A very high degree of variation in shearing ranging about $70^{\circ}$ in both clockwise and anticlockwise directions has been detected in the folds of the study area. The shearing and strain patterns have also been examining by observing their amount and direction in the next above and below layers. The patterns are suggestive that the most dominant folding mechanism has been the flexure-shear for the folds of the study area. Flattening strain in these folds must have been overprinted obviously in subsequent deformations after the fold formation which might have modified the original shearing too. The possibility that the original shear patterns also get modified when the folds occur in the vicinity of a shear zone in the study area, cannot be ruled out.

\section{Acknowledgements}

The authors are thankful to the facilities provided by the Head as well as Coordinator CAS, Geology Department, Banaras Hindu University, Varanasi, India. RK is thankful for the RG National Fellowship.

\section{References}

Agarwal, A., Agarwal, K. K., Bali, R., Chandra, P., Joshi, G., 2016. Back-thrusting in Lesser Himalaya: Evidence from magnetic fabric studies in parts of Almora Crystalline zone, Kumaon Lesser Himalaya. J. Earth System Science 125, 873-884.

Agarwal, K.K., Sharma, V.K., 2011. Quaternary tilt-block tectonics in parts of Eastern Kumaon Himalaya, India. Zeitschriftfür Geomorphologie N.F. 55, 197-208.

Agarwal, K.K., Jahan, N., Agarwal, A., 2010. Modification of Fold Geometry in Almora Crystalline Shear Zone, Lesser Himalaya. J. Geol. Soc. India 75, 411-414.

Azmi, R.J., Paul, S.K., 2004. Dolomite of Inner Kumaun Lesser Himalaya: Implication on age and correlation. Current Science 86, 1653-1660.

Banerjee, S., Matin, A., Mukul, M., 2015. Overburden-induced flattening structure in the Himalaya: mechanism and implication Current Science 109, 1814-1820.

Bastida, F., 1993. A new method for geometrical classification for large data sets of folds. J. Structural Geology. 15, 69-78.

Bastida, F., Bobillo-Ares, N.C., Aller, J., Toimil, N.C., 2003. Analysis of folding by superposition of strain pattern. J. Structural Geology, 25, 1121-1139.

Bhargava, O.N., Frank, W., Bertle, R., 2011. Late Cambrian deformation in the Lesser Himalaya. J. Asian Earth Sci. 40, $201-212$.

Bhattacharyya, K., Ahmed, F., 2016. Role of initial basin width in partitioning total shortening in the Lesser Himalayan foldthrust belt: Insights from regional balanced cross sections. J. Asian Earth Science. 116, 122-131

Bhattacharya, A.R., 1978. A mathematical expression for the length of a folded layer. Geoscience Journal, IV, pt. 2, 99-104.

Bhattacharya, A. R., 2008. Basement rocks of the Kumaun-Garhwal Himalaya: implications for Himalayan tectonics. J. Earth Science. India I (I), 1-10.

Chamyal, L. S., 1991. Stratigraphy of the Lesser Himalayan rocks in Kumaun. J. Earth System Science 100, 293-306.

Chakrabarty, S.K., 2016. Geology of the Himalayan Belt: Deformation, Metamorphism, Stratigraphy. Elsevier.

Dieterich, J.H., Carter, N.L., 1969. Stress history of folding. American Journal Of Science. 263, 129-154.

Dubey, A.K., 2014. Understanding an orogenic belt: Structural Evolution of the Himalaya, Springer. 
Elliott, D., 1965. The quantitative mapping of directional minor structures. J. Geol. 73, 865-880.

Hudleston, P.J., 1973. Fold morphology and some geometrical implications of theories of fold development. Tectonophysics 16, 1-46.

Hudleston, P.J., Holst, T.B., 1984. Strain analysis and fold shape in a limestone layer and implication for layer rheology. Tectonophysics 106, 321-346.

Jade, S., Mukul, M., Gaur, V.K., Kumar, K., Shrungeshwar, T.S., Satyal, G.S., Kumar, R., Dumka, Jagannathan, S., Ananda, M.B., Dileep Kumar, P., Banerjee, S., 2014. Contemporary deformation in the Kashmir-Himachal, Garhwal and Kumaon Himalaya: significant insights from 1995-2008 GPS time series. J. Geodesy 88, 539-557.

Jain, A. K., Anand, A., 1988. Deformational and strain patterns of an intracontinental collision ductile shear zone-an example from the Higher Garhwal Himalaya. J. Structural Geology 10, 717-734.

Jain, A. K., Ahmad, T., Singh, S., Ghosh, S.K., Patel, R.C., Kumar, R., Agarwal, K.K., Perumal, R.J., Islam, R., Bhargava, O.N., 2012. Evolution of the Himalaya. Proc. Indian National. Science Academy. 78, 259-275.

Jain, A.K., Dasgupta, S., Bhargava, O.N., Israil, M., Perumal, R.J., Patel, R.C., Mukul, M., Parcha, S.K., Adlakha, V., Agarwal, K.K., Singh, P., Bhattacharyya, K., Pant, N.C., Banerjee, D. M., 2016. Tectonics and Evolution of the Himalaya. Proc. Indian National Sci. Acad. 82, 581-604, doi: 10.16943/ptinsa/2016/48469.

Joshi, M., Tiwari, A.N., 2009. Structural events and metamorphic consequences in Almora Nappe, during Himalayan collision tectonics. Jour. Asian Earth Sci. 34, 326-335.

Katiyar, V., Srivastava, H.B., 2012. Fold profile geometry of the rock of the area around Pithoragarh, Uttarakhand. Jour. of Scientific Research, Banaras Hindu University 56,19-24.

Lisle, R.J., 1992. Strain estimation from flattened buckled folds. J. Struct. Geol.14, 369-371.

Patel, R.C., Kumar, Y., Lal, N., Kumar, A., 2007. Thermotectonic history of the Chiplakot Crystalline Belt in the Lesser Himalaya, Kumaon, India: Constraints from apatite fission-track thermochronology. J. Asian Earth Sci. 29, 430-439.

Patel, R.C., Adlakha, V., Singh, P., Kumar, Y., Lal, N., 2011. Geology, Structural and Exhumation history of the Higher Himalayan Crystallines in Kumaon Himalaya, India. J. Geol. Soc. India 77, 47-72.

Ramsay, J.G., 1967. Folding and Fracturing of Rocks. McGraw Hill, New York,568.

Ramsay, J.G., Huber, M.I., 1987. The Techniques of Modern Structural Geology: Folds and Fractures, Vol. 2. Academic Press, London, 309-700.

Rao, D.R., Sharma, R., 2009. Petrogenesis of the Granitoid Rocks from Askot Crystallines, Kumaun Himalaya. Jour. Geol. Soc. India 74, 363-374

Rao, D.R., Sharma, R., 2011. Arc magmatism in eastern Kumaun Himalaya, India: A study based on geochemistry of granitoid rocks. Island Arc 20, 500-519.

Shah, J., Srivastava, D.C., Joshi, S., 2012. Sinistraltranspression along the Main Boundary Thrust in Amritpur area, Southeastern Kumaun Himalaya, India. Tectonophysics 532-535, 258- 270

Roberts, D., Strömgard, K.E., 1972. A compression of natural and Experimental strain pattern around fold-hinge zones. Tectonophysics 14, 105-120.

Rupke, J.L., 1974. Stratigraphy and structural evolution of the Kumaun Lesser Garhwal Himalaya, Sedi. Geol. 11, 81-265.

Sanderson, D.J., 1976. The superposition of compaction and plane strain. Tectonophysics 30,35-54.

Singh, P., Patel, R.C., Lal, N., 2012. Plio-Pliestocene in-sequence thrust propagation along the Main Central Thrust zone (Kumaon- Garhwal Himalaya, India): New thermochronological data. Tectonophysics 574-575,193-203.

Srivastava, H.B., 1995. Two Dimensional Strain estimation from weakly deformed rocks. Annale Tectoncae. IX, 3-6.

Srivastava, H.B., 2003. Strain determination from concentric folds. Tectonophysics 364, 237-241.

Srivastava, H.B., Sinha, L.K., 1987. Study of fold profile geometry in the rocks of Stengel area, Garhwal Himalaya, U.P., Bull. Indian Geologists Association 20, 139-145.

Srivastava, H.B., Sinha, L.K., Katiyar, V., 2011. Mesoscopic structures from the area around Satengal, Lesser Garhwal Himalaya. J. Scientific Research, Banaras Hindu University 55, 25-34.

Srivastava, V., Gairola, V.K., 1997. Classification of multilayered folds based on harmonic analysis: example from central India. J. Structural Geology. 19, 107-112.

Srivastava, V., Gairola, V.K., 1999. Geometrical classification of multi-layered folds. Tectonophysics 301,159-171.

Srivastava, V., Gairola, V.K., 2003. Recent classification schemes for multilayered folds: An overview. Milestones in petrology (Ed. Mohan, A.), Memoir of the Geological Society of India 52, 395-408.

Tiwari, M., 2008. Additional Neoproterozoic sponge spicules from Gangolihat Dolomite, Kumaun Lesser Himalaya, India. Himalayan Geology. 29, 49-55.

Tiwari, M., Pant, I., 2009. Microfossils from the Neoproterozoic Gangolihat Formation, Kumaun Lesser Himalaya: Their stratigraphic and evolutionary significance. J. Asian Earth Science 35, 137-149.

Twiss, R.J., Moores, E.M., 2007. Structural Geology, W. H. Freeman, New York.

Valdiya, K. S., 1980. Geology of Kumaun Lesser Himalaya. Wadia Institute of Himalayan Geology.Dehradun.

Valdiya, K.S., Pande, K., 2009. Behavior of basement-cover decoupling in compressional deformation regime, northern Kumaun (Uttarakhand) Himalaya. Proc. Indian Nat. Sci. Acad. 75, 27-40.

Verma, A.K., Bhattacharya, A.R., 2011. Reorientation of lineation in central crystalline zone, Munsiari-Milam area of the Kumaon Greater Himalaya. J. Earth System Science 120, 449- 458.

Zagorčev, I.S., 1993. The geometric classification of folds and distribution of fold types in natural rocks. J. Structural Geology 15 , 243-251.

(c) 2019 Journal of Geoscience, Engineering, Environment and Technology. All rights reserved. This is an open access article distributed under the terms of the CC BY-SA License (http://creativecommons.org/licenses/by-sa/4.0/). 